\section{Relações entre profissionais de saúde e mulheres HIV+: uma abordagem de gênero}

\author{
Relationship between health care professionals \\ and HIV positive women: a gender approach
}

Janaína Marques de Aguiar 1

Regina Helena Simões-Barbosa ${ }^{2}$

\footnotetext{
1 Escola Nacional de Saúde Pública Sergio Arouca, Fundação Oswaldo Cruz, Rio de Janeiro, Brasil.

2 Núcleo de Estudos em Saúde Coletiva, Universidade Federal do Rio de Janeiro, Rio de Janeiro, Brasil.

Correspondência J. M. Aguiar

Departamento de Ciências Sociais, Escola Nacional de Saúde Pública Sergio Arouca Fundação Oswaldo Cruz. Rua Leopoldo Bulhões 1480 Rio de Janeiro, $R J$ 21041-210, Brasil. jamaragui@gmail.com
}

\begin{abstract}
This article presents the results of research in 2003 focusing on the relationship between health care professionals from a public clinic and HIV positive women, adopting a gender approach. Ten patients and seven attending professionals were interviewed on the following themes: gender representations; representations of HIVIAIDS in women; and accommodation and resistance strategies to internalized attitudes and values regarding the health professional/patient relationship. According to the results, health professionals attempted to adjust the treatment to the limited resources of both the institution and the patient, endeavoring to offer the most complete care possible. Their social imagery continues to portray the traditional role of woman/mother/wife, perceived as a victim. Meanwhile patients adopted a "fighting woman" image, reinforced by the "modern woman" ideology, produced in both public and private spheres, disguising the effects of the women's double workload. Contrary to the myth of passivity, patients took an active stance towards their treatment, negotiating with health professionals about their own needs and objective possibilities. Despite the material and symbolic limitations, the potential was identified for changes in health care in order to achieve full reproductive rights.
\end{abstract}

Acquired Immunideficiency Syndrome; Women; Health Services
A resistência e a demora em reconhecer a vulnerabilidade da população feminina em face da epidemia de AIDS mais uma vez denunciam uma sociedade que reforça e atualiza as desigualdades de gênero. Com a estreita colaboração das ideologias médica e de gênero, historicamente entrelaçadas, a imagem da mulher/mãe/ esposa, até recentemente considerada protegida desse "mal", possibilitou, a partir dos anos 1980, uma rápida e silenciosa disseminação do vírus HIV entre as mulheres ocidentais 1.

Tomado aqui em seu sentido crítico, o conceito de ideologia designa as formas simbólicas que sustentam relações de dominação e exploração ${ }^{2}$. A ideologia de gênero refere-se ao substrato simbólico que define uma identidade social para as mulheres, em que a função reprodutiva ocupa lugar central, sustentando e reproduzindo a subordinação social destas 1,3 . A ela entrelaçada, a ideologia médica produz um discurso que, por um lado, naturaliza e, por outro, medicaliza o corpo feminino, circunscrevendo-o ao lugar reprodutivo, a despeito da massiva e explorada inserção das mulheres no mundo produtivo ${ }^{4}$. Essas diversas instâncias ideológicas estão permanente e organicamente imbricadas e atuam num mesmo sentido, de manutenção do poder pelos grupos dominantes, assegurando a reprodução de desigualdades sociais e de gênero ${ }^{3}$. No que tange à assistência à saúde, os profissionais dessa área, especialmente os médicos, sujeitos a essas secu- 
lares representações da medicina sobre o corpo e a sexualidade feminina, geralmente não concebem as mulheres como sujeitos com direitos e desejos a serem considerados e respeitados 3 . Por isso, a necessidade de se considerarem as especificidades femininas nas ações de enfrentamento da epidemia de AIDS vem esbarrando nessas ideologias, que obscurecem e inviabilizam estratégias preventivas e curativas adequadas.

O tratamento para a AIDS feminina vem sendo prioritariamente definido pela infectologia, que, por meio de protocolos de intervenção medicamentosa sobre as mulheres HIV+, busca, em última instância, reduzir o número de crianças infectadas perinatalmente 1,3 . Desse modo, as mulheres têm sido pouco consideradas em pesquisas que esclareçam interações medicamentosas potencialmente danosas à saúde feminina. Essa abordagem contraria não só os princípios de integralidade, eqüidade, descentralização e horizontalização das ações de saúde definidos pelo Sistema Único de Saúde (SUS), mas também o próprio modelo assistencial proposto pelo Programa Integral de Assistência à Saúde da Mulher (PAISM), que tem a integralidade e a promoção de direitos reprodutivos como meta central 5 .

Nesse complexo cenário, este artigo apresenta e discute parte dos resultados de uma pesquisa realizada em 2003 que investigou as relações entre profissionais de um serviço público de saúde e suas pacientes HIV+ em torno do tratamento para HIV/AIDS. Para tal, adotamos como referencial o conceito de gênero, o qual postula que, para além da diferença apenas sexual, as representações de gênero correspondem, na prática, a posições sociais com diferentes significados, para homens e mulheres, nas relações que estabelecem entre si e com o seu meio, sendo, portanto, constituintes da identidade de todo indivíduo ${ }^{6}$. Logo, o sujeito é constituído por meio de códigos lingüísticos e representações culturais nas suas relações tanto de sexo, quanto de raça/etnia e classe. Sendo assim, representar-se ou ser representado como masculino ou feminino subentende a totalidade desses atributos sociais 3,6,7,8,9,10.

Nesse sentido, assume-se que as posições de gênero das mulheres HIV+, entrelaçadas às suas inserções de classe e raça/etnia, perpassam o âmbito do tratamento clínico. Os profissionais de saúde, por sua vez, também sujeitos de gênero, têm suas posturas profissionais pautadas por ideologias - médica e de gênero - que perpassam suas relações com as pacientes.

Porém, tal como proposto por Anyon 11, postulamos que a construção das identidades de gênero envolve um permanente processo de acomodação e resistência que implica respostas ativas das mulheres às ideologias contraditórias de papéis sexuais. Conseqüentemente, $o$ desenvolvimento do gênero implica tanto recepção passiva quanto resposta ativa às contradições sociais. Assim, nosso enfoque sobre as representações simbólicas dos atores sociais objeto desta pesquisa - mulheres HIV+e profissionais de saúde - levará em conta a reprodução de ideologias e os mecanismos de resistência a elas.

Valendo-nos desses referenciais, buscamos captar, através das falas das pacientes e dos profissionais entrevistados, quando e como suas representações e ideologias de gênero perpassam e estruturam as relações profissional/paciente em torno do tratamento da AIDS, com foco especial nas estratégias de acomodação e/ou resistência adotadas na construção e manutenção dessa relação. Dessa forma, esperamos poder contribuir para a melhoria da qualidade na assistência à saúde das mulheres HIV+, promovendo e respeitando, como preconiza o PAISM, o direito ao exercício pleno e consciente da sexualidade e da cidadania 6 .

\section{Metodologia}

Por esta pesquisa estar inserida no campo da subjetividade e das representações simbólicas, elegeu-se a metodologia qualitativa. A abordagem para interpretação dos dados foi a hermenêutica-dialética, conforme proposta por Minayo 12. A união dessas duas concepções trata as manifestações simbólicas, como a linguagem e o trabalho do pensamento, como expressões históricas, resultantes de um processo social e de conhecimento, cada qual com significados específicos, mas articulados entre si 12 .

O campo de estudo foi um ambulatório para o tratamento de doenças infecto-parasitárias (DIP), de um hospital público no Município do Rio de Janeiro. Foram realizadas 17 entrevistas semi-estruturadas, sendo sete com profissionais que estivessem atuando no programa há no mínimo um ano e dez com mulheres HIV+ fazendo uso de medicação anti-retroviral (ARV) e em acompanhamento regular com a equipe há mais de um ano. À medida que a doença torna-se crônica, a "adesão ao tratamento" configura-se como desafio, por isso, consideramos o uso dos ARV um diferencial significativo nas relações das pacientes com o seu adoecimento e com a equipe de saúde. O critério para o número de entrevistas foi o ponto de saturação dos temas. 
Os temas abordados com as pacientes e os profissionais foram as representações de gênero, as representações sobre a AIDS e o adoecimento, os significados de ser mulher HIV+e, por fim, como essas representações perpassam as relações estabelecidas por estes atores em torno do tratamento.

As falas apresentadas são identificadas por um código contendo a letra M para mulheres/ pacientes e $\mathrm{P}$ para os profissionais, a fim de que se percebam as múltiplas interfaces destes discursos.

A pesquisa foi submetida aos devidos Comitês de Ética em Pesquisa e respeitou os princípios contidos na Declaração de Helsinki (http:// www.wma.net/e/policy/b3.htm, acessado em 20/Nov/2004).

\section{Perfil dos entrevistados}

A idade das pacientes entrevistadas variou entre 23 e 55 anos, com prevalência na faixa dos 30 anos. A maioria tinha moradia própria e apresentava baixa escolaridade, com inserção empregatícia no ramo de prestação de serviços. Metade tinha renda familiar acima de três salários mínimos (um salário mínimo equivalia a $\mathrm{R} \$ 240,00$ ), e a outra metade situava-se abaixo desse patamar. Três entrevistadas exerciam alguma atividade profissional, três estavam desempregadas, duas licenciadas, uma aposentada e outra se declarou "do lar".

Nove entrevistadas tinham filhos, todos soronegativos; seis tinham mais de um filho e cinco tinham filhos maiores de 18 anos. Quatro entrevistadas já eram avós, três das quais ajudavam a criar os netos. No que se refere à situação conjugal, metade das entrevistadas vivia sem parceiro há, no mínimo, dois anos. Todas as demais tinham parceria estável, variando entre 2 e 18 anos de união; apenas uma tinha parceiro (sabidamente) HIV+. Todos os parceiros trabalhavam no ramo de prestação de serviços.

Os sete profissionais entrevistados tinham entre 27 e 61 anos, sendo a maioria mulheres (6), em união estável e com filhos. O tempo de serviço na instituição variou entre 2 e 31 anos, o que mostra profissionais em momentos de vida e de carreira distintos. Esclarecemos que o critério para escolha dos profissionais foi serem membros de uma mesma equipe de saúde, o que pressupõe uma identidade e uma relação profissional mais estreita. $\mathrm{O}$ amplo predomínio de mulheres na equipe trouxe implicações de gênero que a pesquisadora não ignorou. Entretanto, não fez parte do objetivo deste estudo analisar relações de gênero "entre”, mas sim "com" esses profissionais.

\section{Identidade de gênero: \\ "a mulher guerreira"}

Quando levadas a repensar o seu lugar na sociedade na qualidade de mulheres, agora associado à condição de portadoras do HIV+, a maternidade emerge, na fala das pacientes entrevistadas, como um atributo biológico que justifica e, assim, naturaliza as mulheres como seres mais fortes que os homens: "Sempre ponho meu filho em primeiro plano (...) ele que é minha força de viver, ele que me faz viver (...) se meu filho depende de mim e do meu marido, então eu tenho que pensar no dia seguinte, sempre no dia seguinte, porque ele é muito pequeno pra ficar aí sozinho" (M6).

Assim, ao confrontarem suas experiências de vida com o estereótipo da fragilidade/passividade feminina, surgiu, entre as pacientes entrevistadas, a representação da mulher "sexo forte", mais bem preparada para o enfrentamento das dificuldades cotidianas, inclusive aquelas trazidas pela AIDS: "Nascer mulher com a disposição que eu tenho, com a garra que eu tenho (...) sou uma mulher guerreira, lutadora, igual ele (o marido) fala, ele chora nos meus pés, ele fala assim: 'Você é muito guerreira, passar o que você passou, na situação que você tá aí com esse problema aí, com essa doença!' (...) isso aí não é nada, eu sou guerreira, se eu tivesse que nascer mulher eu ia nascer de novo (...) com a disposição que eu tenho" (M3).

Surge, então, na fala dessa entrevistada, a contraditória imagem da "mulher guerreira": aquela que dá conta do trabalho doméstico e do remunerado, do cuidado e, muitas vezes, do sustento de filhos e netos, tendo, ainda, que cuidar da sua própria saúde. Essa imagem se coaduna com o que Giffin 13 caracterizou como representação ideológica: uma "nova mulher", autônoma, independente, com maior controle sobre sua sexualidade e maior atuação no mercado de trabalho, o que pode estar encobrindo a intensificação da exploração do trabalho feminino, marcado pela persistência da dupla jornada de trabalho dentro e fora do âmbito doméstico, contribuindo para a reprodução das desigualdades de classe social e gênero.

Nesse sentido, essa dupla jornada de trabalho é naturalizada pelas pacientes entrevistadas e justificada pela capacidade "natural" de as mulheres-mães assumirem mais encargos que os homens. Muitas delas já exerciam essa dupla atribuição nas famílias de origem, cui- 
dando de irmãos menores e ajudando no sustento familiar por meio de trabalhos precários; mesmo assim, essa sobrecarga de tarefas e atribuições, produtivas e reprodutivas, não foi por elas questionada: "Isso é o normal praticamente de todas as mulheres que trabalham fora. (...) muitas vezes eu tô estressada, não consigo nem ouvir a voz de ninguém dentro de casa (...) Mas é normal, é o dia-a-dia (...) hoje em dia (...) nós, mulheres, somos pai, mãe, chefe de família, então a minha vida se torna assim, como milhares e milhares de outras" (M10).

Por outro lado, os efeitos dessa ideologia da "nova mulher" foram percebidos e problematizados pelas profissionais entrevistadas, que expressaram seu esgotamento com a dupla jornada de trabalho que, no limite, não lhes deixa tempo para cuidarem da própria saúde: "Parece que o tempo da gente não dá pra nada (...) porque aí você lembra 'tenho que ir ao dentista, não marquei', não marquei porque tô envolvida com isso e aquilo, acabo esquecendo de mim mesma (...) você começa a podar uma série de coisas pessoais, da sua saúde, da sua vida que vão ficando em segundo plano" (P2).

Contudo, embora essa representação ideológica da "nova mulher" abarque a maioria das mulheres, são as mais pobres as que mais sofrem com as contradições entre tal ideologia e sua realidade concreta, marcada pela dura luta pela sobrevivência material e poucas possibilidades de realização pessoal, o que aponta para as conexões entre desigualdades de classe e de gênero.

Apesar dessas diferenças entre mulheres, as profissionais entrevistadas revelaram, em seus discursos, confluências, identificações e solidariedade de gênero com suas pacientes, especialmente aquelas infectadas por seus maridos "dentro de casa”. "Imagino que deve ser duro pra uma mulher (...) descobrir que ela tá com AIDS $e$ (...) que essa doença foi trazida pelo marido que, além de trair, ainda teve esse (...) descuido aí, de não se preocupar com o que ele (...) tava trazendo pra casa" (P4).

Os profissionais também demonstraram sensibilidade para perceber o quanto a maternidade é uma experiência fundamental e estruturante da identidade feminina, independente da classe social.

"Quando elas tão a fim de ser mães, a ligação com o filho é um negócio assim impressionante (...) a vontade que elas têm é de ficar em casa mesmo, lambendo a cria. E eu acho que isso aí é instintivo, é natural, eu acho que isso aí é da mulher..." (P5).

Admitem, todavia, ser esta uma questão bastante delicada e complexa quando se trata de mulheres HIV+ que desejam ser mães. A gestação, nessa situação, é sempre considerada "de risco", tanto para a mãe e o bebê, quanto para o próprio parceiro que, se não for portador do vírus, pode vir a se infectar. As falas de dois profissionais são ilustrativas das dimensões desse dilema no cotidiano da assistência: "Quando você tira a capacidade de uma paciente de ser mãe, você tá mutilando ela (...) como se ela tivesse feito uma histerectomia ou, pior, aquilo tá lá funcionando, mas ela não pode usar..." (P5).

"Quando nasce um filho, a gente tem uma razão de continuidade, a gente tem muitas razões de continuidade. Acho que a mulher (...)é muito aquinhoada pela natureza quanto a isso (...) e aí vem uma doença que abala totalmente a idéia de imortalidade que o homem possa ter, e isso é dramático na mulher" (P3).

Para algumas das pacientes entrevistadas, 0 drama por não terem um filho em razão do HIV significa sua "incompletude" como mulheres. Uma vez que a maternidade também representa uma prova de amor ao parceiro "saudável" e uma forma de estreitar os laços afetivos do casal, não poder garantir um filho "saudável" fere a identidade feminina, o que pode abalar o vínculo conjugal. Knauth 14, ao investigar como o HIV incide sobre as decisões reprodutivas, também constatou que, entre outros aspectos, as decisões das mulheres HIV+ de levar adiante ou não uma gravidez relacionam-se com o tipo de aliança conjugal existente: as que resolveram manter a gravidez estavam em fase de consolidação da aliança, e ter um filho significava fortalecer esse vínculo.

Elas se vêem, portanto, no dilema entre o desejo de constituir uma nova família ou consolidar a já existente, o medo de expor a criança à infecção e mesmo não ter como lhe garantir os cuidados necessários em virtude de seu próprio adoecimento. Ainda assim, a maternidade se revela, para essas mulheres, como sinal de vida e esperança, em contraposição à idéia de morte associada à AIDS 4: "As pessoas falam que Deus botou minha filha ali com a doença, pra mim ficar resistindo (...) porque, assim, se eu não tivesse minha filha eu tinha feito uma besteira (...) eu tenho que ficar mais com a minha filha, viver mais com a minha filha, pra ver ela crescer" (M5).

Para alguns profissionais, a responsabilidade no cuidado com os filhos pode ser tanto a principal motivação para que as pacientes se cuidem, quanto a razão pela qual não se tratam adequadamente. A diferença entre um caso e outro vai depender do suporte sócio-familiar de que essas mulheres dispõem, especialmente de suas próprias mães: “Geralmente (...) a mãe 
dessa paciente dá uma... segurada nas coisas, você vê que isso atenua muito todos esses problemas. Quando não têm uma mãe por trás delas... a gente vê que complica (...) quando a mãe dessa paciente não entra, a vida se torna muito mais difícil (...) é mãe ou avó (...) isso aí é o que segura a vida dela" (P5).

De fato, metade das pacientes entrevistadas revelou ter em suas mães o apoio necessário para enfrentar as dificuldades trazidas pela doença, o que representa, além de cuidar, também ser cuidada. Ao mesmo tempo, esse referencial de figura materna pode reforçar a identidade de mulheres/guerreiras que, como mães, são responsáveis pelo cuidados dos outros, negligenciando os cuidados consigo próprias.

A sexualidade é outro tema que assume especial relevância na constituição da identidade feminina; assim como a maternidade, é uma questão profundamente complexa, seja para as mulheres $\mathrm{HIV+}$, seja para os profissionais que as assistem. Embora estes reconheçam como saudável o fato de essas mulheres não anularem sua sexualidade por causa da AIDS, as medidas de prevenção e os alertas para os riscos de transmissão estão permanentemente presentes em suas falas, o que remete aos históricos discursos médico-pedagógicos de controle sobre a sexualidade feminina.

Entretanto, apesar desse discurso normatizador, os profissionais entrevistados não deixaram de perceber e considerar as implicações culturais e as desigualdades nas relações de gênero das pacientes, em que o uso de preservativos, especialmente em parcerias estáveis, nem sempre é viável, como demonstrado por alguns estudos 15. Essa reflexão se estendeu para o contexto das suas próprias relações amorosas, explicitando, novamente, as identificações de gênero e as solidariedades entre profissionais e pacientes: "Eu mesma pensei: 'Bom, tô aqui falando pras mulheres se prevenirem. E eu, o que eu tô fazendo?' (...) porque o homem, ele (...) sempre teve aí o lugar de (...) mandar nas relações, de exigir, querer ou não querer fazer" (P4).

Por outro lado, para algumas pacientes, emergiu a representação de uma sexualidade "contaminada” pela AIDS, o que demanda um rígido controle. O sexo, responsável pela infecção de 9 entre as 10 entrevistadas, passa a representar uma espécie de "zona de perigo", na qual é preciso ter cuidado com o outro e consigo mesma. Diante da AIDS, o desconhecimento sobre o próprio corpo e a repressão sobre a sexualidade são atualizados na história de vida de cada mulher infectada.

Assim, para três entrevistadas, abrir mão de qualquer prática sexual configura-se como úni- co caminho viável de prevenção e proteção de si e do outro, evitando a exposição de sua condição sorológica e a possibilidade de discriminação.

“Eu não vou poder arrumar uma pessoa (...) bem de saúde (...) que não tenha o vírus, porque (...) eu acho que, mesmo usando camisinha, você corre um risco (...) agora eu tenho que ter consciência que eu não devo passar isso mais pra ninguém..." (M4).

A estreita relação ideológica entre reprodução e sexualidade feminina na assistência à saúde das mulheres toma, portanto, proporções ainda mais drásticas diante da AIDS: ou as mulheres HIV+ reprimem sua sexualidade em nome da proteção de si mesmas e do outro, cerceando seus direitos reprodutivos, ou assumem os riscos de uma gravidez; neste caso, as ações do serviço de saúde passam a ter como objetivo final impedir a transmissão vertical para o bebê 3,4 .

\section{A relação profissional/paciente: estratégias de acomodação e resistência}

As pacientes entrevistadas expuseram, através de seus relatos, o dramático impacto que um diagnóstico de HIV/AIDS tem em suas vidas. Sem poder retornar ao estado de "saúde" anterior, essas mulheres passam a sentir-se com uma marca que as faz diferentes das demais e que, mesmo quando assintomáticas, conferelhes uma sentença de doente em potencial - se não estão agora, podem ficar a qualquer momento. As relações que estabelecem com suas experiências corporais e seus referenciais de saúde passam, então, a ser pautadas pelo rótulo de "portadoras do vírus da AIDS", uma doença ainda reconhecida pela ciência e pela sociedade como transmissível e incurável.

Uma série de regras e novas necessidades relacionadas ao tratamento - rígidos horários para medicação, alimentação adequada, consultas e exames laboratoriais regulares - passam a mediar o cotidiano dessas mulheres. Na tentativa de viabilizar o tratamento, resguardar o sigilo sobre seu estado sorológico e adaptarse à dinâmica institucional, elas adotam diversas estratégias adaptativas, tais como adiantar os afazeres domésticos na véspera da consulta (para evitar o acúmulo de afazeres domésticos), ou pedir dispensa do trabalho alegando outros motivos para ir ao hospital. Não relegar os encargos domésticos para um segundo plano, mesmo para se tratarem, pode ser interpretado como uma estratégia de acomodação à ideologia de gênero que naturaliza o trabalho domés- 
tico como responsabilidade exclusivamente feminina.

$\mathrm{O}$ tratamento, embora signifique maior e melhor qualidade de sobrevida para a maioria das entrevistadas, também é vivido como uma sobrecarga de responsabilidades. Além de cuidar dos outros, elas agora têm que cuidar mais e melhor de si mesmas, inclusive para que possam continuar desempenhando seus encargos, tanto doméstico-familiares, quanto produtivos: "Você tá tonta, enjoada, querendo só ficar sentada (...) pra esperar aquilo (...) melhorar, $e$ não pode, tem que ir atender, eles não entendem por que a mamãe não pode ir agora (...) aí isso me cansa, os dias que eu não tô me sentindo bem, tem que ir trabalhar..." (M2).

As pacientes que aderem ao tratamento, apesar de todas as dificuldades enfrentadas, também são reconhecidas por alguns profissionais como "guerreiras" e, quanto mais se aproximam deste perfil, mais são valorizadas. Por outro lado, a fala de um dos profissionais revela o quanto essa imagem de "guerreira" pode ser ideologicamente naturalizada como um atributo de mulheres de baixa renda, mais afeitas às duras labutas da vida: "Ela não desiste porque estar com saúde pra ela é o melhor, ela sabe disso, ela pode continuar trabalhando, pode continuar cuidando dos filhos (...) elas são umas desbravadoras, lutadoras, elas continuam porque elas trazem isso já da luta delas" (P3).

Ainda assim, as pacientes revelam-se agentes ativos nas relações que estabelecem com os profissionais, adotando estratégias que lhes garantam um vínculo empático e, até certo ponto, com mais autonomia sobre o tratamento. Sendo assim, avaliam os profissionais segundo critérios tais como capacidade técnica, disponibilidade para a escuta, afetividade, paciência e clareza nas informações transmitidas. A preferência por esse perfil de profissional, além de possibilitar uma proximidade afetiva com eles, facilita a compreensão e incorporação dos termos técnicos que utilizam: "Com a gente, ele examina, ele explica o que tá acontecendo (...). E o Dr. Beltrano não, ele não explicava, assim, com detalhes pra mim entender (...); agora tô entendendo porque antes eu não entendia, eles falavam pra mim, eu parecia uma analfabeta, não entendia nada" (M6).

A apropriação dessa linguagem "tecnicista", ao mesmo tempo em que facilita o manejo do tratamento, possibilita que elas adotem a postura da "paciente que não dá trabalho". Tal estratégia pode ser interpretada como, simultaneamente, de acomodação a um modelo que espera a obediência da "paciente" e de resistência a este mesmo modelo, com a adoção de uma postura ativa que busca o domínio de termos e procedimentos técnicos, o que lhes confere poder. Em ambos os sentidos, as pacientes também reproduzem o discurso pedagógico normatizador sobre prevenção e controle da epidemia: “... de aconselhamento, eu acho assim que, se eu sou soropositivo, mesmo sendo as duas (pessoas) não pode transar sem camisinha, $e$ uma que tenha e a outra não tenha, ela também tem que usar camisinha pra não contaminar a outra que não tem (...) sempre fui dessa opinião. Os médicos aqui me apóiam, me adoram porque eu sou assim, é o meu jeito (...) só porque eu vou morrer, eu vou levar fulano comigo?" (M3).

Para a maioria das pacientes entrevistadas, prevaleceu o reconhecimento dos profissionais de saúde, especialmente os médicos, como autoridades “inquestionáveis", uma vez que são eles que detêm o saber e, correlatamente, o poder, sobre a doença e o tratamento. O que não significa que não haja resistências quanto às decisões médicas, especialmente no que se refere ao uso da medicação. Logo, omitir o fato de não estar tomando os remédios também é utilizado como estratégia para manter um bom relacionamento com os profissionais e garantir a manutenção do vínculo com a instituição. Afinal, assumir que se está indo contra uma decisão médica é assumir que se está sozinho, por sua própria conta e risco.

Os profissionais, por sua vez, no intuito de driblar limites pessoais, profissionais e as dificuldades cotidianas trazidas pela deficiência de recursos institucionais, e buscando viabilizar uma melhor assistência às pacientes, adotam medidas tais como: interná-las para conseguir, via parecer interno, a realização de exames de outras especialidades clínicas; colher e entregar pessoalmente o material para exame no laboratório; levar seu próprio material instrumental para as consultas; utilizar sua influência política dentro da instituição, na forma de favor pessoal, para conseguir a intervenção de outras especialidades ou vagas para internação; buscar pessoalmente prontuários e exames que estejam faltando no momento do atendimento; procurar soluções junto com as pacientes e solicitar diretamente a colaboração de familiares para potencializar suas redes de apoio. Essas medidas, além de configuraremse como uma estratégia de resistência à crescente escassez de recursos materiais e humanos no setor público de saúde, também revelam o envolvimento pessoal e profissional desta equipe com as necessidades das pacientes.

Esses profissionais demonstraram grande sensibilidade ao reconhecerem que, para uma boa adesão ao tratamento, é fundamental que 
este se adapte às possibilidades objetivas de vida das pacientes e não o contrário, como usualmente proposto pelo modelo assistencial hegemônico. A fala de uma profissional revela os meandros desta sensibilidade: “Às vezes eu tô prescrevendo um remédio (...) que eu sei que cada comprimido custa 15,00 (...) tem que tomar 5 por dia, 5 dias, isso aí ela não ganha nem num mês (...) então, algumas vezes eu evito dizer que aquilo é essencial. Então, eu passo o Aciclovir pro herpes, aí falo assim: 'se você conseguir no posto, tudo bem, mas se não tiver não tem problema não'. Porque se não, vai gerar uma angústia na paciente..." (P7).

Contudo, ainda persistem tentativas de adequar as pacientes às regras do tratamento, o que pode ser evidenciado em um discurso pedagógico normativo no qual vigoram as seguintes prescrições: obrigatoriedade do uso de preservativos nas relações sexuais; uso correto da medicação; rígida prevenção da gravidez, alegando-se a possibilidade de complicação clínica para a mãe, o bebê e o parceiro; manutenção do equilíbrio emocional com vistas a minimizar a queda de imunidade e o provável aumento da carga viral, entre outros. A utilização de tal discurso é captada, sobretudo, na fala das próprias pacientes, ao reproduzirem-no: "É como os médicos falam, que se a pessoa ficar deprimida é pior, aí é que os vírus se multiplicam, tem que pensar que eu vou viver muito" (M6).

D'Oliveira \& Shraiber 16, em estudo sobre as práticas de saúde analisadas sob a ótica de gênero, apontam para o entrelaçamento das ideologias médicas e de gênero, mesmo em serviços de saúde que, em tese, orientam-se pelas ações programáticas do PAISM. As autoras ressaltam a permanência do uso da autoridade por parte das profissionais de saúde - imbuídas do poder médico -, até quando buscam o empowerment das usuárias do serviço, preconizando normas e valores de relacionamento jamais pretendidos por estas em suas relações com seus parceiros e também na forma de lidar com o próprio corpo. Ocorre, portanto, uma transposição da autoridade técnica em autoridade moral, na qual o discurso "libertário" das profissionais impõe-se sobre os desejos e necessidades das usuárias.

Conseqüentemente, compreendemos que a permanência desse discurso normativo por parte dos profissionais entrevistados, ainda que com sua sensível reflexão sobre as dificuldades de vida das pacientes, revela a complexidade das estratégias de acomodação e resistência ao modelo biomédico vigente e às ideologias, médica e de gênero, que nele subjazem. Nesse sentido, ao mesmo tempo em que o vín- culo afetivo é por eles acionado para reforçar a adesão das pacientes ao tratamento, a realização, em alguns casos, de uma consulta formal, técnica e, portanto, distante, protege-os de entrar em contato com difíceis e complexas questões de vida trazidas para o âmbito da consulta, configurando uma estratégia de acomodação a um modelo baseado no distanciamento emocional em prol do êxito profissional, como revela este depoimento (auto)crítico: "Eu acho que, quando a gente (...) vai somando os anos de medicina, a gente cria uma barreira, sempre cria uma barreira, a gente sempre consegue separar, eu acho que é por isso que a gente fala tanto em doença, às vezes a gente identifica o paciente não como pessoa, mas como doença" (P5).

Igualmente, quando se esbarra em algum limite pessoal ou técnico, passar o caso para outro profissional pode ser interpretado, simultaneamente, como estratégia de resistência, quando se busca a possibilidade de um melhor atendimento para a paciente, e de acomodação, quando se transfere o "problema" para outro colega.

"Aí é quando a gente encaminha mais pra psicologia porque (...) aquele peso inicial você ainda consegue suportar, mas uma coisa que já é antiga, crônica (...) acho que já (...) sai um pouquinho da nossa esfera..." (P7).

Doença e tratamento, portanto, revelam ter, na prática, fronteiras bastante nítidas no que se refere à atuação dos diversos profissionais, estabelecidas tanto por estes, quanto pelas pacientes. Diante disso, a consulta médica é vista, por ambos atores, como um espaço destinado a tratar das questões relacionadas ao tratamento ARV e à sintomatologia clínica; as questões sociais e econômicas encontram legitimidade na consulta com a assistente social; e as questões emocionais são acolhidas pelo profissional de psicologia. Essa segmentação da assistência é reforçada pela própria organização do serviço, na qual o médico "identifica" o problema que, se não for "orgânico", será encaminhado para outra especialidade. Esses dados confirmam os achados de pesquisa anterior 4 . A intenção final é oferecer à paciente todos os recursos disponíveis dentro da instituição, embora permaneça distante da perspectiva da integralidade, tal como proposta pelo PAISM.

Esse inovador programa buscou operacionalizar o conceito de assistência integral à saúde da mulher através de uma proposta educativa horizontal e participativa, baseada no diálogo e na troca de experiências entre usuárias e profissionais, ambas tomadas como sujeitos de gênero. Essa proposta inovadora de educação em saúde visou a fortalecer a auto-estima das 
usuárias, oferecendo-lhes a possibilidade de decidirem sobre suas questões de vida e saúde em consonância com seus desejos e necessidades, tendo como base conhecimentos articulados com suas representações e práticas cotidianas 5,17. Assim, as oficinas educativas devem possibilitar um espaço de troca e reflexão de vivências tanto para pacientes, quanto para profissionais, estes entendidos como agentes de mudança 18. No entanto, como constatado, esse modelo de assistência está perpassado por contradições e conflitos entre o tradicional modelo médico e as novas práticas propostas, o que aponta para a necessidade de profundas transformações no modelo assistencial para sua efetiva implementação 16 .

\section{Considerações finais}

O presente estudo possibilitou-nos captar e compreender alguns aspectos das complexas e contraditórias relações de gênero que se estabelecem entre profissionais de saúde e mulheres HIV+ no âmbito da assistência à saúde, o que nos desafia a um olhar mais amplo sobre as questões relacionadas à saúde e aos direitos reprodutivos de mulheres HIV+ assistidas nos serviços públicos de saúde. O PAISM, tomado como modelo assistencial, viabilizou uma reflexão crítica a respeito do serviço pesquisado sob a ótica de seus agentes: profissionais e usuárias.

Buscamos apreender, por intermédio da fala dos profissionais e das pacientes entrevistados, o sistema de representações que modela a construção das relações estabelecidas em torno do tratamento para a AIDS. As falas dos profissionais revelaram a permanência de ideologias médicas e de gênero nas relações profissional/paciente, o que se evidencia através de prescrições normativas, autoritárias e/ou de cunho tecnicista.

Contudo, esses profissionais não se revelaram reprodutores passivos do modelo hegemônico de assistência à saúde. Pelo contrário, seus esforços se voltam para um trabalho que viabilize um atendimento mais integral, humano e de qualidade às mulheres HIV+. Todavia, a integralidade ainda é entendida, por estes, como a disponibilidade de uma equipe multidiscipli- nar que procura responder de forma segmentada às diversas necessidades trazidas pelas pacientes, e não como decorrência de uma concepção e atuação efetivamente integrada na assistência à saúde das mulheres HIV+.

Entre as pacientes entrevistadas, evidenciou-se uma postura ativa na relação que estabelecem com seu adoecimento e com os profissionais de saúde. A maioria delas são mães, esposas, donas de casa e trabalhadoras que se autodenominam "guerreiras" por resistirem a toda sorte de dificuldades, às quais a AIDS vem se somar. Entendemos que, no contexto do tratamento de AIDS, essa imagem de "guerreira" pode servir para as pacientes como uma estratégia de resistência à vitimização socialmente imputada à mulher HIV+ infectada por seu parceiro e uma forma de resistir aos impactos físicos, psicológicos e sociais causados pela doença, uma vez que representar-se como guerreira fortalece a auto-estima e instiga a crença de que a doença não usurpará suas identidades de mãe, esposa e trabalhadora.

Ao mesmo tempo, essa imagem da "mulher guerreira", que assume quase todas as responsabilidades, permanece naturalizada e pode estar atuando como estratégia de acomodação às demandas sociais impostas por este ideal de "nova mulher", justificando e perpetuando uma situação de dominação e exploração das mulheres, particularmente as da classe trabalhadora.

Porém, no difícil e precário contexto das instituições públicas de saúde no Brasil, consideramos que as pacientes e os profissionais entrevistados buscam resistir mais do que se acomodar às inúmeras dificuldades enfrentadas cotidianamente, o que nos mostra um importante potencial para lutarmos pela efetiva implementação do PAISM.

Finalmente, evidenciamos o quanto a situação de pobreza das pacientes perpassa o campo da assistência para o HIV/AIDS, apontando para os limites provocados pela pauperização e feminização da epidemia na prática cotidiana dos serviços públicos de saúde. Coloca-se, dessa forma, a necessidade urgente de maiores investimentos em políticas públicas que reduzam os crescentes níveis de desigualdades sociais em nosso país. 


\section{Resumo}

O artigo apresenta os resultados de uma pesquisa, realizada em 2003, que investigou, sob a ótica de gênero, as relações entre profissionais de saúde e suas pacientes HIV+ em torno do tratamento oferecido. Foram realizadas entrevistas semi-estruturadas com dez mulheres HIV+e sete profissionais de saúde a respeito dos temas: representações de gênero; representações sobre o adoecimento feminino por HIVIAIDS; estratégias de acomodação e resistência a valores e atitudes internalizados, utilizadas nas relações profissional/paciente. Os dados revelaram que os profissionais buscam adequar o tratamento à precariedade de recursos da instituição e das pacientes, buscando oferecer uma assistência o mais integral possivel. Ainda permanece no imaginário coletivo deles a representação da mulhermãe, percebida como vítima. Entre as pacientes, emerge a representação da "mulher-guerreira", reforçada pela ideologia de gênero que obscurece a sobrecarga resultante da dupla jornada de trabalho. Contrariando o mito da passividade, as pacientes assumem posturas ativas no tratamento, negociando com os profissionais suas necessidades e possibilidades. Apesar das limitações materiais e simbólicas, identificaram-se potenciais para transformações na assistência, rumo à conquista de Direitos Reprodutivos.

Sindrome de Imunodeficiência Adquirida; Mulheres; Serviços de Saúde

\section{Colaboradores}

J. M. Aguiar participou da concepção, redação e revisão deste. R. H. Simões-Barbosa colaborou na redação, edição e revisão do artigo.

\section{Agradecimentos}

Agradecemos à Coordenação de Aperfeiçoamento de Pessoal de Nível Superior pela bolsa de estudos concedida à pesquisadora principal.

\section{Referências}

1. Vermelho LL, Simões-Barbosa RH, Nogueira SA. Mulheres com AIDS: desvendando histórias de risco. Cad Saúde Pública 1999; 15:369-79.

2. Thompson JB. Ideologia e cultura moderna: teoria social crítica na era dos meios de comunicação de massa. Petrópolis: Editora Vozes; 1995.

3. Simões-Barbosa RHS. Mulheres, reprodução e AIDS: as tramas da ideologia na assistência à saúde de gestantes HIV+ [Tese de Doutorado]. Rio de Janeiro: Escola Nacional de Saúde Pública, Fundação Oswaldo Cruz; 2001.

4. Giffin K. Corpo e conhecimento na saúde sexual: uma visão sociológica. In: Giffin K, Costa SH, organizadores. Questões da saúde reprodutiva.
Rio de Janeiro: Editora Fiocruz; 1999. p. 79-91.

5. Costa AM. Desenvolvimento e implantação do PAISM no Brasil. In: Giffin K, Costa SH organizadores. Questões da saúde reprodutiva. Rio de Janeiro: Editora Fiocruz; 1999. p. 319-35.

6 De Lauretis T. A tecnologia do gênero. In: Holanda HB, organizador. Tendências e impasses: o feminismo como crítica da cultura. Rio de Janeiro: Rocco; 1994. p. 206-41.

7. Saffioti HIB. Rearticulando gênero e classe social. In: Costa AO, Bruschini C, organizadores. Uma questão de gênero. Rio de Janeiro: Rosa dos Tempos/São Paulo: Fundação Carlos Chagas; 1992. p. 183-215.

8. Kergoat D. Relações sociais de sexo e divisão sexual do trabalho. In: Lopes MJ, Meyer DE, Waldow VR, organizadores. Gênero e saúde. Porto Alegre: Artes Médicas; 1996. p. 19-27.

9. Giffin K. Pobreza, desigualdade e eqüidade em saúde: considerações a partir de uma perspectiva de gênero transversal. Cad Saúde Pública 2002; 18 Suppl:103-12.

10. Brito JC. Enfoque de gênero e relação saúde/trabalho no contexto de reestruturação produtiva e precarização do trabalho. Cad Saúde Pública 2000; 16:195-204.

11. Anyon J. Interseções de gênero e classe: acomodação e resistência de mulheres e meninas às ideologias de papéis sexuais. Cad Pesqui 1990; (73): 13-25.

12. Minayo MC. O desafio do conhecimento: pesquisa qualitativa em saúde. São Paulo: Editora Hucitec/Rio de Janeiro: ABRASCO; 1998.

13. Giffin K. Esfera da reprodução em uma visão masculina: considerações sobre a articulação da produção e da reprodução de classe e de gênero. Physis (Rio J) 1994; 4:23-40.

14. Knauth D. Maternidade sob o signo da AIDS: um estudo sobre mulheres infectadas In: Costa AO, organizador. Direitos tardios. Saúde, sexualidade e reprodução na América Latina. São Paulo: Programa de Treinamento em Pesquisa sobre Direitos Reprodutivos na América Latina e Caribe, Fundação Carlos Chagas/Editora 34; 1997. p. 39-64.

15. Simões-Barbosa RHS. AIDS e saúde reprodutiva: novos desafios. In: Giffin K, Costa SH organizadores. Questões da saúde reprodutiva. Rio de Janeiro: Editora Fiocruz; 1999. p. 281-96.

16. D'Oliveira AFPL; Shraiber LB. Violência de gênero, saúde reprodutiva e serviços. In: Giffin, K, Costa SH, organizadores. Questões da saúde reprodutiva. Rio de Janeiro: Editora Fiocruz; 1999. p. 337-55.

17. Aguiar AC. Contribuições da pedagogia feminista para a educação em saúde da mulher. In: VI Congresso de Saúde Coletiva. Rio de Janeiro: ABRASCO; 2000.

18. Giffin K. Estudos de gênero e saúde coletiva: teoria e prática. Saúde Debate 1995; 46:29-33.

Recebido em 09/Mar/2005

Versão final reapresentada em 09/Set/2005

Aprovado em 16/Fev/2006 